\title{
Beyond the Hype: A Bibliometric Analysis Deconstructing Research on Digitalization
}

\author{
Andrea Holand, Silje Svadberg and Karl Joachim Breunig \\ " Taxonomy is described sometimes as a science and sometimes \\ as an art, but really it's a battleground. "'
}

Bill Bryson

Author

\begin{abstract}
The accelerating emergent field of research addressing digitalization and related topics is complex, unstructured and hyped. Consequently, both research and practice lack a rigorous foundation of prior published research to underpin and direct future exploration into the opportunities and challenges provided by these exciting new digital technologies. This study employed a bibliometric analysis to explore extant published research within the digitalization field. We identified key articles that have enabled us to distinguish between interrelated digitalization concepts. Subsequently, we propose a taxonomy with characteristics for different levels of digitalization. The taxonomy contributes dimensions that create different commercial and organizational opportunities and challenges at various levels. The taxonomy offers a vantage point for subsequent empirical and conceptual research to extend insights on related digitalization themes, and especially those related to innovation and strategy decisions on scalability, automation, channel selection and connectivity.
\end{abstract}

\section{Introduction}

Anything relating to digitalization is certainly in vogue these days, and academic research is in fast pursuit. Currently, much of the research in this area is explanatory or conceptual, and not empirical, and exists in case studies that are spread across different disciplines (for example, strategy, management, innovation, and informatics). An initial search on Google Scholar reveals an overwhelming amount of suggested articles for search terms, such as: "digitalization" with 58,100 links, "digital disruption" with 5,570 links, or "digital transformation" with 25,500 links. In addition to this abundance of published research, much attention is now on digital technology developments driven by technology vendors. Reports describe new types of digital technologies such as: Internet of Things (IoT), machine learning (ML) and artificial intelligence (AI), virtual and augmented reality (VR and AR), or blockchain, to mention a few. A number of reports, for instance by consultancy firms, also give speculative estimates of the numbers of workers that will be affected by these technologies. In short, the accelerating emergent field of research that addresses "digitalization" and related topics is complex, unstructured and hyped. Consequently, both research and practice lack a rigorous foundation of prior published research to underpin and direct future exploration into the new digital technologies.
A prerequisite condition to obtain a clearer picture of the contemporary phenomenon of digitalization is to achieve an overview of it, that goes beyond the current hype. There is a need to extend prior research that attempted to provide conceptual clarifications (e.g. Nambisan et al, 2017; Yoo et al., 2012; Yoo et al., 2010) and a uniform definition and taxonomy of the multiple and interrelated terms used in current digitalization research. The ambition of this paper is therefore to address the following research question: How can the concept of digitalization be framed into a rigorous conceptual foundation that can support research and practice alike?

To explore the research question we employed a structured literature search to extract a final search database that could be used for bibliometric analysis, and to identify key articles for content analysis. The search resulted in an initial sample of 1307 articles, which were reduced to 197 for our bibliometric analysis, thus resulting in a final sample of 18 articles upon which we conducted content analysis. Moreover, we utilized bibliometric analysis to identify key articles that enabled us to distinguish between digitalization concepts. On this basis we are now able to propose a basic taxonomy. This taxonomy includes different levels of digitalization, relating to several dimensions that create varied organizational and commercial opportunities and challenges. The taxonomy offers a vantage point for 


\section{Beyond the Hype: A Bibliometric Analysis Deconstructing Research on Digitalization Andrea Holand, Silje Svadberg and Karl Joachim Breunig}

subsequent empirical and conceptual research to extend insights on related digitalization themes, especially related to innovation and strategy decisions on scalability, automation, channel selection and connectivity.

\section{Theory}

McAfee (2009) refer to "digitalization" as the pace of change in society driven by digital technological development, involving multiple technologies at different stages of maturity that will converge and create new technologies. There exists no established consensus framework within digitalization theory. While digitalization has been a topic in information systems research for decades, the current wave of digitalization is different, according to Legner et al. (2017): it is driven by us. This calls for a broader field of research to merge efforts that deal with the complexity of this development, and to further our understanding of the impact of digitalization, and its potential societal, organizational and commercial implications. Similar to Legner et al., Brenner et al. (2014) argue that the power unlocked in information technology (IT) is shifting to users who are increasingly expecting sophisticated digital services and products.

The increasing expectations from users and the rapid innovation of IT within the last three decades is putting pressure on leaders in commercial and public organizations that are being challenged by disruptive start-ups, calling for a better understanding of how different levels of digitalization will impact their business. IT innovation has come along with the development of new systems, software applications and standards that support and shape business activities in various ways, many that are forcing organizations to deal with an increasing amount of data, and acting in complex and growing networks (Heilig et al., 2017). This environment of continuing technological change, according to Heilig, Lalla-Ruiz and Voß (2017), may require or even promote shifts in organizational structures, processes, and strategies. This further underpins the need for structuring digitalization research especially in regards to organizational impact. Additionally, while some argue technological advances drives digitalization, Kane et al. (2015) conducted research wherein they suggest that strategy, not technology, drives DT. They found that maturing digital businesses are focused on integrating digital technologies in the service of transforming how their businesses work, and that talent engagement and business model innovations have a clear digital strategy in organizations where digital technologies have transformed processes (Kane et al., 2015). Correspondingly, there is an increasing acknowledgement of the important organizational implications of digitalization emerging within both research fields of information systems and organization science (e.g. Lyytinen et al., 2016; Nambisan et al., 2017; Tilson et al., 2010; Yoo et al., 2010). However, extant digitalization research remains fragmented, and a majority of studies remain focused on technological complexity, rather than with understanding the organizational complexity in which technology is implemented and utilized (Andal-Ancion et al., 2003).

Moreover, there exists a plethora of interrelated terms, such as digization, digitization, digitalization and DT (Negroponte, 2015). Researchers have defined the terms digitization, digitalization and digital transformation in previous research (Loebbecke \& Picot, 2015; Negroponte, 1995; Aron \& Waller, 2014; Andal-Ancion et al., 2003). However, these terms are applied differently in different studies and are suggested to address everything from stages (Loebbecke \& Picot, 2015) in the development of different applications and types of digital technology, to the ambition underpinning the utilization of these technologies. Furthermore, there exists no clarity regarding which concept is appropriate to use for describing each different digital process, and the benefit this process seeks to achieve. Indeed, there are several conceptualizations of each term, and to date no consensus exists on the different levels of digitalization. Also related is the term "disruption", which refers to a situation where existing companies are substituted or replaced by new ones (Bradley et al., 2015).

While the Industrial Revolution in the late eighteenth century relieved manual labour, the second machine age of the current era, with computers and other digital advances are predicted to relieve cognitive tasks (Brynjolfsson \& McAfee, 2014). Recently, several waves of advances in digital technology have fundamentally transformed business and society, contributing to the complexity of the field (Legner et al., 2017). The first wave focused on converting analogue to digital information, leading to higher automation in work routines. The second wave established the Internet as a global communications infrastructure, resulting in, for example, changes in a firm's value creation logic, along with new types of businesses. The third wave, which we are experiencing today, involves converging SMAC (social, mobile, analytics, and cloud) technologies that have brought the vision of omnipresent computing much closer to reality. Moreover, digitalization is constituted by a variety of emerging technologies at different stages of maturity and market acceptance. It has been 


\section{Beyond the Hype: A Bibliometric Analysis Deconstructing Research on Digitalization Andrea Holand, Silje Svadberg and Karl Joachim Breunig}

suggested that these will converge and mutually strengthen each other in a kind of digital revolution (Manyika et al., 2013).

Notably, two main dimensions have been identified to enable comprehending the different emerging types of technology (Brynjolfsson \& McAfee, 2014). First, increased machine power, including emerging technologies such as AI, big data, augmented reality, advanced robotics, autonomous vehicles and 3Dprinting. Second, increased connectivity, including technologies such as mobile internet, social media, audion and video conferencing, IoT, cloud and fog, as well as blockchain. The combined effect of all of these emerging technologies on employees, customers and organizations is as of yet unknown. All of these technologies are assumed to have large consequences for firms in marketing and business model innovations (BM) (Ng \& Wakenshaw, 2017). Similar to the widely accepted assumption that these technologies in combination are likely to have a considerable impact on expert based businesses (Jesuthasan, et al., 2016), existing research has also pointed to professional service firms as a type of business where the impact of digitalization will be greatest (Manyika et al., 2013; Zott \& Amit, 2017). This also elucidates how digitalisation, with related themes such as digital disruption and digital transformation (DT), requires conceptual clarification that attends to the contextual complexities associated with utilizing digital technologies in different industries. Accordingly, there is a need for extending prior research based on a taxonomy that helps clarify how digital strategy and digital innovation can be practised across different industries, beyond the current conception of digitalization as a homogeneous phenomenon.

Consequently, we see a pressing need to take stock of the body of current published research addressing the organizational implications of digitalization, and related terms, placing a specific emphasis on how different concepts are characterised, as well as describing the relationship between terms.

\section{Methods}

We employ science mapping from the discipline of bibliometrics with the aim to provide a systematic and thorough review of digitalization research, specifically related to disruption and transformation. Bibliometrics refer to "the collection, the handling, and the analysis of quantitative bibliographic data, derived from scientific publications" (Verbeek et al., 2002: 181). A systematic review adopts a replicable, scientific, and transparent process based on the theoretical synthesis of existing studies, thus differing from general reviews (Cook et al., 1997). Structural reviews allow us to, 1) examine relations between topic areas, and 2) use some form of quantification to shortly compile a large amount of literature (Porter, et al., 2002). While the common research paper cites around twenty references, providing an incomplete picture of the research context, a broad literature scan can, according to Porter, Kongthon, and Lu (2002: 351) "extend the span of science by better linking efforts across research domains. Topical relationships, research trends, and complementary capabilities can be discovered, thereby facilitating research projects". In addition, as structural reviews to some degree employ a form of quantification and objective analysis, such reviews "improve the review process by synthesizing research in a systematic, transparent and reproducible manner" (Tranfield, et al., 2003: 207). Thus, structural reviews help overcome one of the traditional review paper's limitations: its lack of rigour.

To provide an objective and systematic review of the literature containing keywords of both one or more of the concepts digit* and either transform* or disrupt*, we employed the VOSviewer science mapping framework (Van Eck et al., 2010; Van Eck \& Waltman, 2014). By using VOSviewer science mapping, we were able to examine in rich detail the intellectual content and structure of research on digitalization concepts linked with transformation and/or disruption. Further we employed content analysis to a selection of papers from our final search database, selecting the papers based on both traditional and bibliometric criteria. The content analysis allowed us to make replicable and valid conjectures by interpreting the textual material.

\subsection{Sample}

A four-stage process was used to identify papers for analysis. First, we searched Web of Science (WoS) for articles using the search string Title $=(($ Digit* AND Transform*) OR (Digit* AND Disrupt*)), thereby identifying 1,307 papers. Second, we excluded only 2019 from the publishing year, keeping all whole years to retain potential developments in the field. Third, we included articles, proceedings papers, book reviews, reviews, book chapters, and editorial material. Fourth, we systematically excluded research categories in WoS that did not contain information about the concepts of digitization, digitalization or DT, thus removing categories focusing on technology description and specifications, rather than digital change. To assess categories relevant to answer our research question, we applied three selection methods based on the number 


\section{Beyond the Hype: A Bibliometric Analysis Deconstructing Research on Digitalization Andrea Holand, Silje Svadberg and Karl Joachim Breunig}

of articles within each category. For categories with 30 or more papers, we performed a bibliographic cooccurrence analysis using a threshold of 5 to identify relevant keywords. Analysing the clusters in each category revealed if articles focused on technological attributes or digitalization concepts. Further, to ensure that high-impact articles within categories that were discarded by the bibliometric analysis were not overlooked, we read the abstracts of the 20 most cited papers for each category. Finally, for categories with less than 30 results, we read the abstract of all papers to assess their relevance. Our final literature search downloaded from WoS following the four step process contained 197 papers.

The same process was performed with a topic search using the same criteria as described above. In this case, clusters from analysing the resulting database revealed keywords mainly related to hardware attributes of technology. Abstract readings further confirmed that the papers in the database mainly described usage of different technologies. Thus, as initial analysis suggested a title search would make us better equipped to answer our research question, we chose to build our paper on a title sample that resulted in a final search database containing 197 papers.

\subsection{Analysis}

The analysis was threefold. First, we performed a descriptive analysis of our final search database to ascertain the history of the field, and its development within journals and disciplines. The purpose was both to identify which disciplines drive digit* research, and to assess the distribution and impact of the various journals. To gain insight into emerging concepts and conceptualization within disciplines, we studied how terms have changed over time, and across journal categories. Second, we did a bibliometric analysis of the final search database in order to classify the relevant keyword clusters for each of the digit* concepts, and to categorize the disciplines associated with the terms. This analysis further enabled us to discover the development of keyword clusters over time, identifying emerging and trending "hot" concepts. Finally, it enabled us to pinpoint the most cited papers and thus helped us learn which main disciplines are referenced in our final search database papers. The bibliometric analysis was also conducted to contribute to literature review by identifying the most influential articles, using a content analysis of the 18 most relevant papers (see Appendix I). This related to our research to identify any conformity and contrast among the digitalization concepts.

\subsubsection{Descriptive analysis}

For the descriptive analysis, we used a final search database and converted this into an Excel file. We added a column for journal category (i.e. People and Organization, Strategy, Technology and IT, Business, Cross-disciplinary work, Economy, Law, Library and archival science and Management), and a column for the "digitalization" concept, both populated manually. Assessment of appropriate value for the journal column was based on the journal's discipline, which was addressed by visiting each journal's website. The appropriate value for the digitalization column was based on three factors: paper title, keywords, and abstract. When all columns were populated with values, the Excel sheet was connected to Microsoft's analytical service Power BI for data visualization.

\subsubsection{Bibliometric analysis}

To obtain a better overview of the identified articles, we saved all 197 articles in one file, thus permitting a thorough bibliometric analysis (Markoulli et al., 2017). To conduct the analysis we applied the VOSviewer software and identified clusters of interrelated digit* articles. We created a Thesaurus file to combine similar words with different spellings, where, for example, the label "Business models" was replaced by "Business model". This was done to ensure more trustworthy clusters. General terms like "Transformation" were not combined with "Digital transformation", as these grasp broader than digital change specifically. Thesaurus was also used for the co-citation analysis, but with the intention to make each point in the clusters more intuitive and the map easier to read visually. Cocitation and Co-occurrence analyses were conducted to compute the relevance of keywords and citations between them, and bibliographic coupling was conducted to find the most influential articles within the final search database. The discipline category for each cluster was identified by doing an Eigenvector Centrality (EC) analysis in Gephi for both the cooccurrence and co-citation separately. The GML files was imported to Gephi with graph type "undirected", indicating that papers are not necessarily referring to each other both ways.

\subsubsection{Content analysis}

To ensure for relevance and identify the unit for further literature review, we did a three step-process to make a selection from the set of 197 articles. First, we read the abstract of all articles to ensure thematic relevance, and selected the ones that informed or defined the phenomenon of digit* terms. During the reading, articles were scored based on their relevance related to 


\section{Beyond the Hype: A Bibliometric Analysis Deconstructing Research on Digitalization Andrea Holand, Silje Svadberg and Karl Joachim Breunig}

the research question, on the following scale: (A) Relevant; (B) Borderline Relevant; and (C) Irrelevant. During this process the papers that didn't contain concepts of digital change were discarded as irrelevant, for example, papers with a core focus on hardware and technological attributes. Second, to ensure papers in our content analysis were based on purely objective criteria, the five articles with the highest citation score, as well as the five papers with the highest EC (that is, network centrality) were included. EC measures approximate importance of each node in the graph, and the core idea in EC is that an important node usually is connected to important neighbours (Wang et al., 2012). Thus, it identifies relevant articles in the final search database with the assumption that each node's centrality is the sum of the centrality values of the nodes it is connected to. To calculate the EC we did a bibliographic coupling analysis in VOSviewer with "Documents" as the unit of analysis, saved the resulting map as a GML file, and imported it to Gephi to complete the analysis. The selection result included 18 out of 197 papers. Of the top five cited papers, four overlapped with the fifteen retrieved from abstract readings. Further, of the top five papers retrieved from EC, two overlapped with the 15 retrieved from the reading of abstracts. For details about the 18 selected articles included in the content analysis, please see Appendix I.

The content analysis was conducted by reading and assessing the 18 papers identified through the three selection criteria. We read all papers and coded them in Excel to provide an overview of how each paper described the respective digit* concept and how the purpose of it was defined. Further, the content analysis was split by collecting information from all digitization-, digitalization-, and DT papers in separate tables to easier identify the content and common features of each concept.

\section{Findings}

Overall, our study reveals that there has been an exponential growth in published digi* themed papers over time, a trend indicating that there might be several research papers in progress and in proceedings (figure $1)$.

Moreover, a majority of these papers are published in lower ranked journals, indicating that research on digital change is primarily represented in smaller and niche journals. The journals are spread across nine different categories, where the strategy category only includes two papers. As strategy is a highly relevant aspect of the digitalization process, the lack of strategy journals writing about these changes indicate that research still remains in its incipient stage (figure 2). We have categorized journals based on subjective criteria, which could be considered a limitation of our data material. Further, the categorization of journals into digital concepts was based on title, abstract, and keyword only, which could be a source of error.

The co-citation analysis we did revealed that there were four different disciplines that most papers referred to, in which method was one of them. Moreover, 30 of the papers in our final search database had citations to qualitative method sources (figure 3), and none to quantitative method sources. This may further indicate

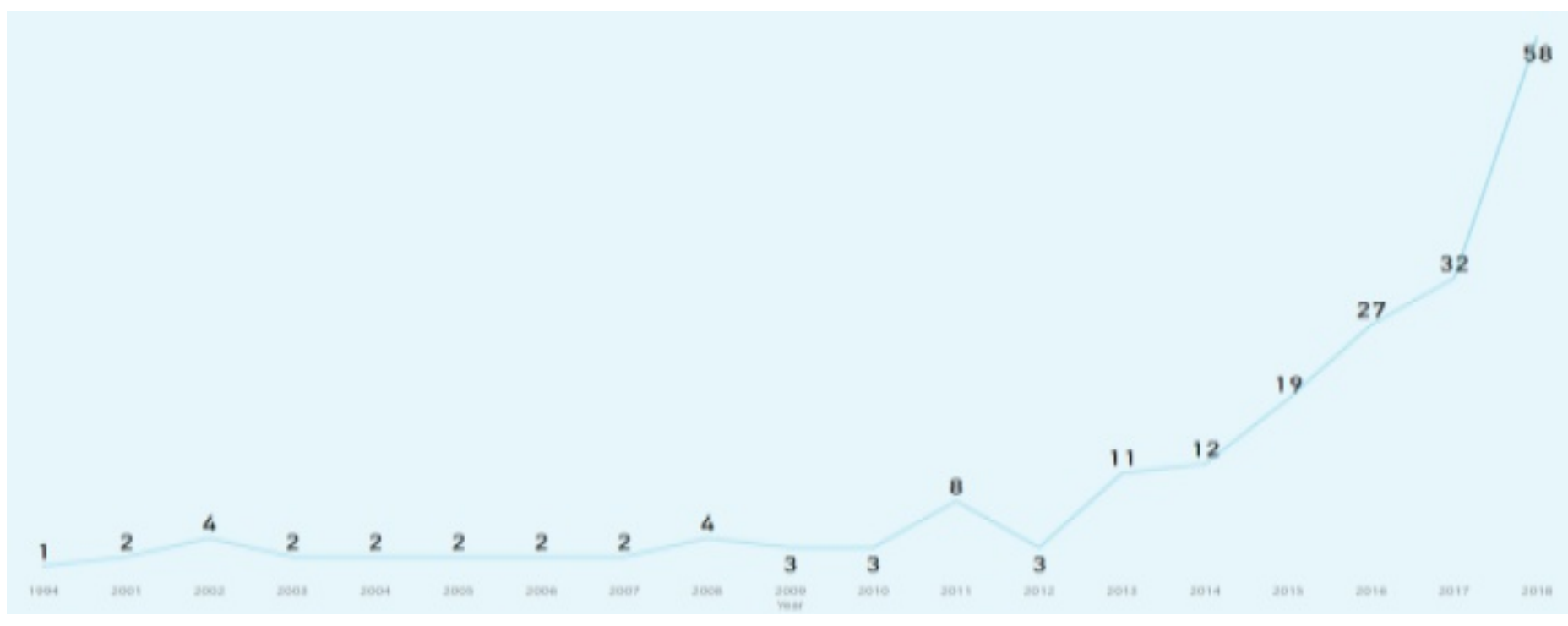

Figure 1. Development in publications per year ( $\mathrm{N}=197$ papers) 


\section{Beyond the Hype: A Bibliometric Analysis Deconstructing Research on \\ Digitalization Andrea Holand, Silje Svadberg and Karl Joachim Breunig}

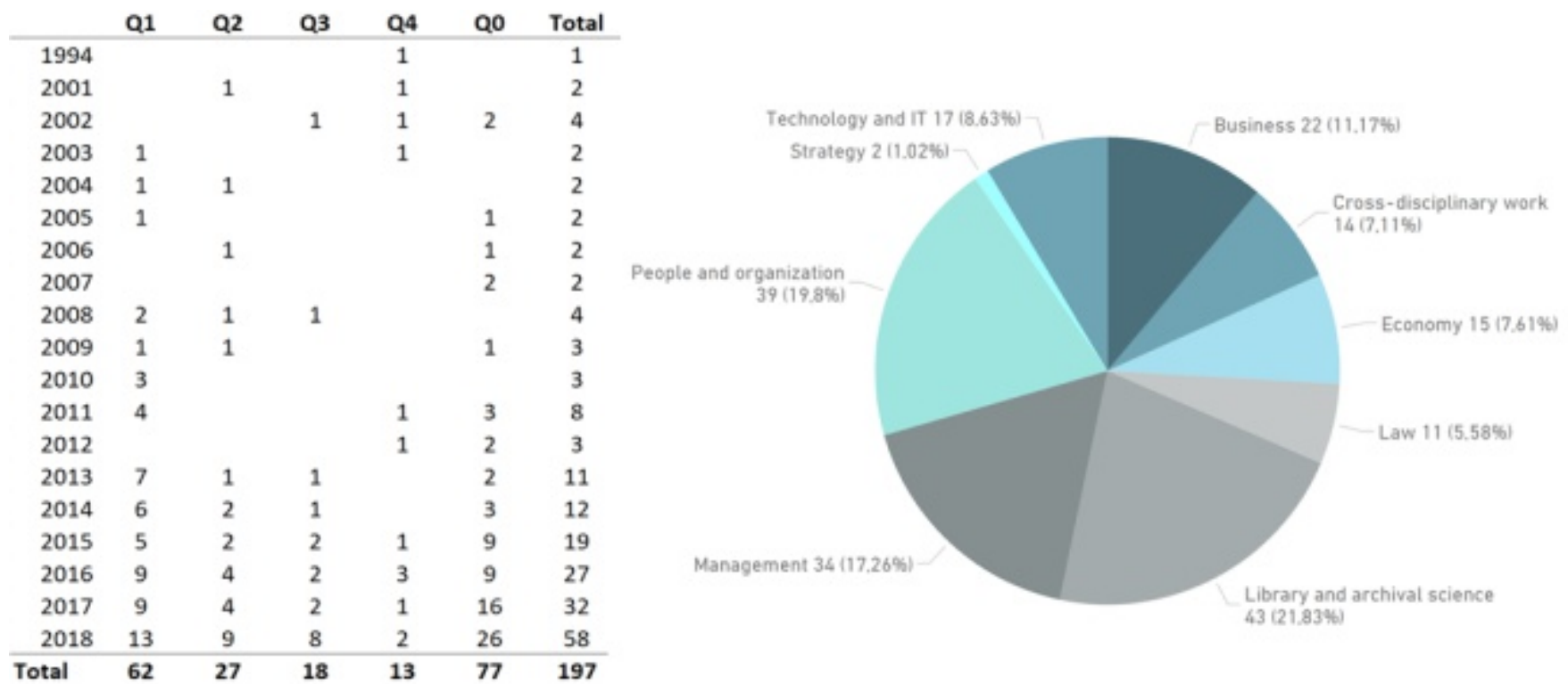

Figure 2. Publication percentage within each SJR category per year

that the research on digitalization is at a young and growing stage.

\subsection{Digitization}

The content analysis revealed a broad consensus on digitization primarily revolving around converting analogue information to digital with the purpose of achieving cost and efficiency goals (see e.g. Bhimani \& Willcocks, 2014; Desai, 2013; Gaigher et al., 2014; Heilig, et al., 2017; Janowski, 2015; Moreau, 2013; Schallmo et al., 2017; Valenduc \& Vendramin, 2017).This is consistent with the findings of bibliometric analysis that disclosed relations between 'digitization' and "Technology". Further, digitization connects with "Organization", "Innovation", and "Management", which also can be explained by findings in content analysis. For example, we find some authors go beyond describing the concept of digitization as a conversion method for storage and information purposes, and rather focus on internal organizational processes at the activities level where it may be used for management purposes by structuring large amounts of data for business, and is seen as a tool to facilitate cost reduction and process automation. Some further describe digitization as a step in the DT process, viewing digitization as a disruptive change through making digitized products available, and thus affecting parts of the $\mathrm{BM}$ and organizational strategy. The content analysis thereby substantiates the findings in our bibliometric co-occurrence analysis (figure 4).

The connection between "digitization" and "Digital transformation" may also be explained by the descriptive analysis, in which most of the papers included in the "Library and archival science" journal category revolved around digitization and DT. This

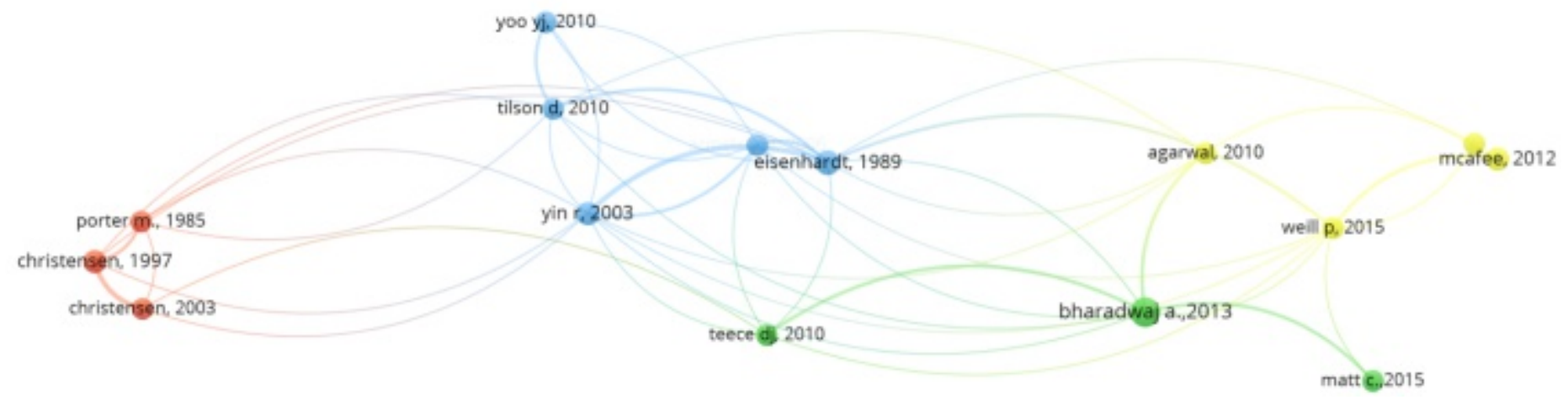

Figure 3. VoS-Viewer map showing co-citation analysis cluster 


\section{Beyond the Hype: A Bibliometric Analysis Deconstructing Research on Digitalization Andrea Holand, Silje Svadberg and Karl Joachim Breunig}

business area traditionally has large amounts of analogue information, and will naturally be affected by digital storage and information sharing opportunities through technological advancements. This may also facilitate value creation, and fundamentally transform BM innovation opportunities. Finally, while a large and consistent number of publications on digitization has accrued, it appears digitization is not a 'hot topic' in digitalization research at this time, as it peaked in February 2016. This may be explained by the large percentage growth in digitalization and DT research in recent years, as digitization is described as a tool in these processes.

\subsection{Digitalization}

According to findings in the content analysis, digitalization is closely related to the concept of digitization. However, authors commonly argue that digitalization goes beyond shifting from analogue to digital information. Digitization can be seen as a part of the digitalization process, where authors describe this level of digitalization as, for example, a sociotechnical process of applying digitizing techniques to a broader social and institutional context, and as a change at the process level through changing organizational structures, internal interactions, and transactions with customers and stakeholders (see e.g. Heilig et al., 2017; Hänninen et al, 2018; Stoeckli et al., 2018; Valenduc \& Vendramin, 2017). This information points to findings in the co-occurrence analysis, where "Technology", "Big data", "Strategy", "Performance" and "Information Technology" relate to digitalization. Further, "Business model" and "Digital transformation" are closely related to digitalization, and findings in the content analysis suggest that digitalization is a tool for BM innovation, as it can contribute to a shift from product to service based BMs, which substantiates the findings in our bibliometric co-occurrence analysis. The content analysis also uncovered that while digitalization, like digitization, focuses on cost and efficiency opportunities, it also revolves around social changes in markets and the workforce, and may facilitate for network and value opportunities.

The descriptive analysis revealed that digitalization is evenly distributed across all journal categories, except

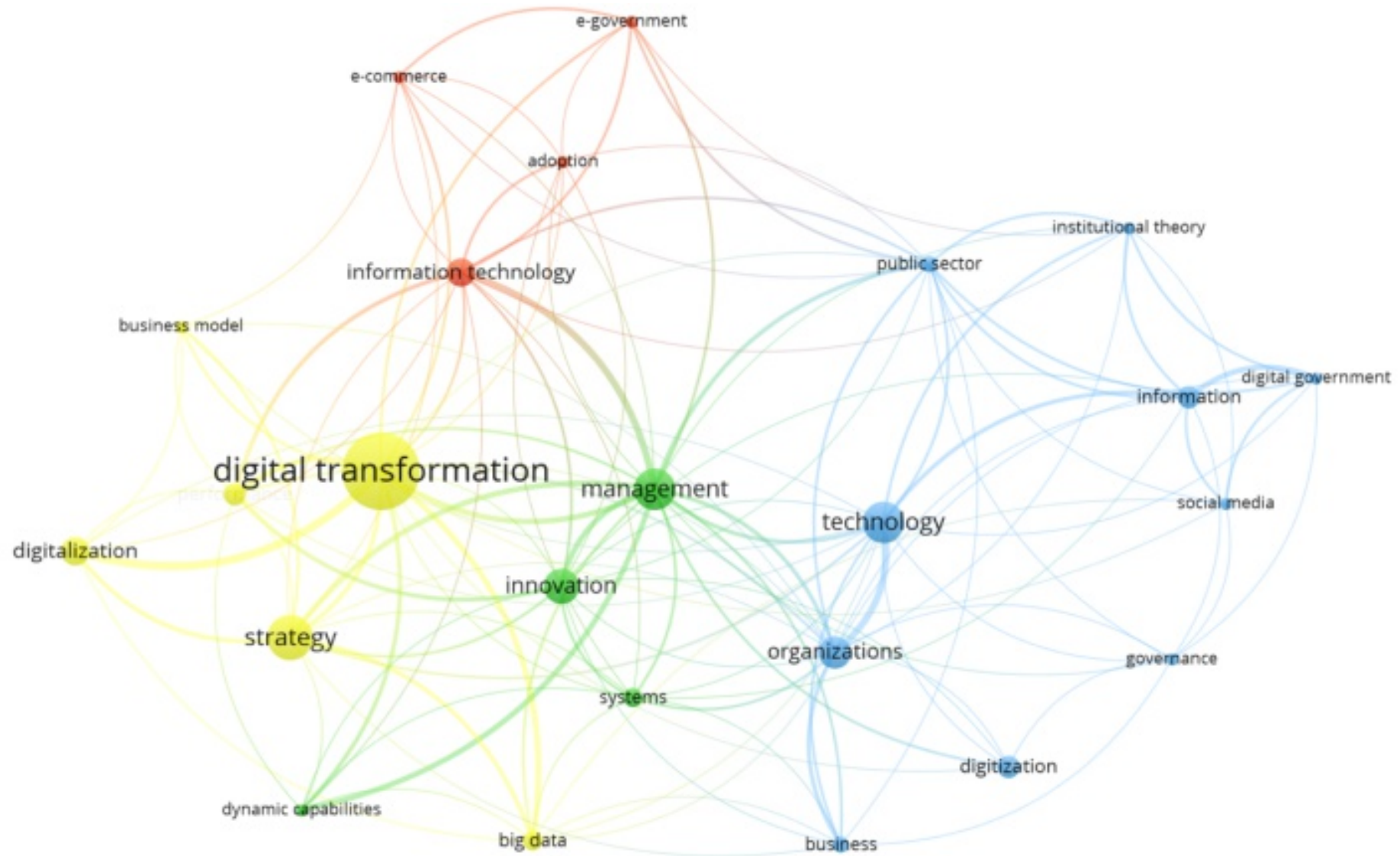

Figure 4. VoS-Viewer map with co-occurrence analysis using keywords as unit of analysis 


\section{Beyond the Hype: A Bibliometric Analysis Deconstructing Research on Digitalization Andrea Holand, Silje Svadberg and Karl Joachim Breunig}

for "Library and archive" and "Strategy". In our final search database, digitalization papers were least represented out of the digit* concepts. However, "digitalization" far preceded the other digitalization concepts when doing our initial search on Google Scholar, which may indicate that this term is used to describe technological attributes, a theme we systematically excluded from our database. The first article involving digitalization in our final search database was in 2014 , followed by a stable distribution of digitalization articles throughout the period 20142018. The number of digitization papers as a percentage of total published each year has however been declining during the period, while publications on this concept peaked in May/June 2017.

\subsection{Digital transformation}

Content analysis revealed that authors commonly agree that DT is concerned with the changes digital technologies can bring about in a company's BM, or BM adaption or transformation as a result of technological progress and innovation (see e.g. Andal-Ancion et al., 2003; Hess et al., 2016; Janowski, 2015; Kotarba, 2018; Liu et al., 2011; Loonam et al., 2018; Schallmo et al., 2017). This substantiates several findings in the bibliometric co-occurrence analysis, for example, that DT relates to "Innovation", "Business models", "Dynamic capabilities", "Performance", "Adoption", and "Organization". Further, while some authors find that part of the purpose of DT is at the organizational process level, the majority agree that it goes beyond the two previous levels of digitalization, and relates to BM innovation in value propositions, networks and relationships. These findings support the relations between "Social Media", "Information Technology", "Systems", "Management", and "Strategy" found in the co-occurrence analysis. The co-occurrence analysis also discloses that this level of digitalization relates to the former two, which may be explained by digitization and digitalization being described as steps in DT. Further, while DT is commonly described as an organizational and ecosystem level change that creates opportunities in value creation, value propositions, networks and relationships, it is noteworthy that cost reduction and efficiency are also mentioned as part of the purpose of DT.

Articles with a primary focus on DT are represented in all journal categories, but the largest share are found in the "Management" and "Technology and IT" categories. Moreover, DT has the largest share of papers in all categories, except in the "Library and archival science" and "Law" categories, where digitization represents the largest share. This may be due to both industries being heavily document and information reliant. Finally, the percentage of DT articles is increasing, and according to our bibliometric overlay visualisation the topic peaked in July 2017.

\section{Conceptualization}

We identified articles that have enabled us to distinguish between concepts, making it possible to suggest a taxonomy (figure 5).

The taxonomy creates several opportunities and challenges on each digitalization level through associated dimensions. It identifies three dimensions (cost reduction, connectivity and value creation) that vary across the three digitalization levels.

The cost reduction dimension involves all three digitalization concepts. Digitization can lead to asynchronous information, opportunities in production scaling, a shorter publishing value chain, better control and customer overview. As for digitalization, it goes beyond digitization as a broader sociotechnical process of applying digitizing techniques on a larger scale to social and institutional contexts, with such things as cost reduction and efficiency as results. Similarly, the

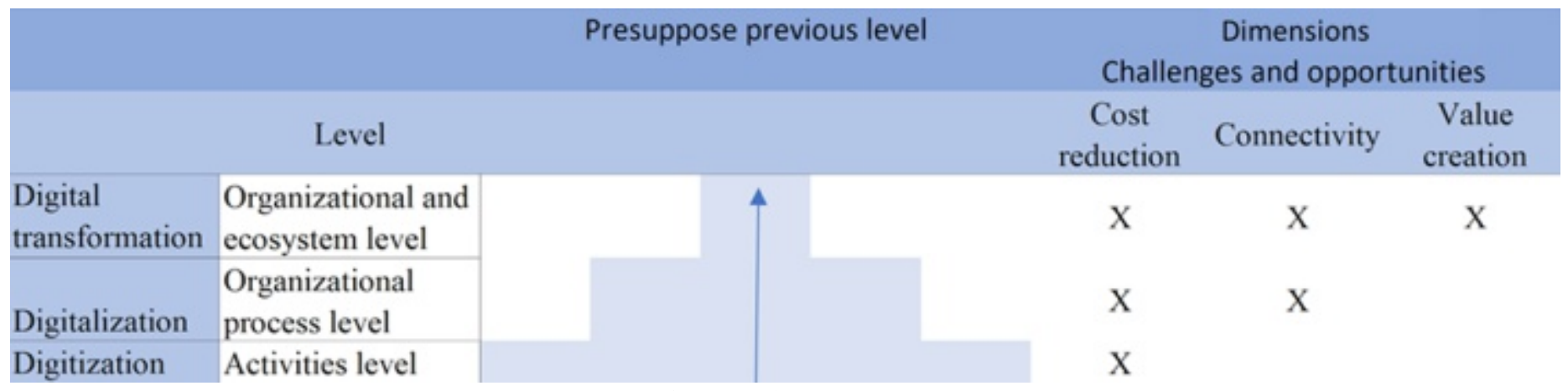

Figure 5. Taxonomy of interrelated digitalization terms with dimensions and levels 


\section{Beyond the Hype: A Bibliometric Analysis Deconstructing Research on Digitalization Andrea Holand, Silje Svadberg and Karl Joachim Breunig}

content analysis revealed that part of the purpose of DT is cost reduction and efficiency, while at the same time having a broader span of opportunities and challenges beyond these benefits. Cost reduction through efficiency gains in the literature are closely related to emerging discussions of automation.

The connectivity dimension comprises both digitalization and DT. For digitalization, it represents an opportunity to connect activities as these are digitalized. The researchers in our content sample overall agree that digitalization will change organizational structures and interactions both internally and externally, affecting how firms compete and transact with customers. For DT the dimension represents an opportunity to cooperate between different actors or create ecosystems, where new, digitally enabled products or services encourage demand via non-traditional methods. The process of DT further poses an opportunity to form new entities and relationships driven by the application of IT, working as an enabler of change to the current paradigms of organizations and individuals. Thus, new partnerships are enabled at this level through usage of advanced technologies, that in turn facilitates instant connectivity and access to growing sources of data that support cross-service opportunities. Connectivity is in literature related to discussions of channel selection and scalability.

In the value creation dimension, DT is represented. Both digitization and digitalization can achieve value through opportunity costs for available resources that can liberate time for other value-retrieving activities. DT on the other hand represents opportunities for value creation, as explicitly uncovered in the content analysis. Changes in value creation due to DT derive from the way in which digital technologies alter a firm's BM. While organizations can go through a BM innovation regardless of whether they include digital processes, the value creation in DT relates to connectivities derived from digitalization (for example, developments in the value proposition related to multi-service platforms, created to attract global customers and service providers). Further, some authors claim value creation in relation to DT stems from how digital strategies and related transformation allow new ways of creating value (for example, co-creation or product and service complementarities through network participation).

Our study reveals that the three concepts of digitalization concern digital change at different levels of the organization. The digitization concept is at the activities level, whereas the other two are at the organizational level, increasingly extending beyond the intra-organizational context into the interorganizational context, and throughout the entire ecosystem. Although it has been claimed that processes can be digitized (e.g. Gaigher et al., 2014), this only describes digitization of existing activities (for example, information, physical or analogue documents, knowledge). Thus, digitization more broadly concerns changing and automating activities that pre-exist in organizations. There is thus a consensus in the articles reviewed that digitalization goes beyond digitization.

Digitalization involves application of technology to broader social and institutional contexts, and thereby contributes to the servitization of organizations, and affects how they compete and interact. Hence, digitalization has an organizational focus on business processes change, related to providing digitally enabled services. Finally, DT is described as a broader process of transforming an organization by affecting the organization's business processes (for example, products, structures, processes, organizational behaviours), and is thus complemented by changes in BMs. DT also facilitates new social networks and new partnership formation, thus relating to changes at the ecosystem-level.

\section{Conclusion}

By conducting a structured assessment of extant published research to address the question, How can the concept of digitalization be framed into a rigorous conceptual foundation that can support research and practice alike?, this paper provides a foundation for studying the currently hyped phenomenon of digitalization and related topics, such as digital disruption and DT.

The study confirms that the field remains immature and fragmented, and despite revealing that all identified articles in our sampled content analysis address digitalization as an important aspect of changes in organizations and related strategy development, few strategy journals deal with digit* concepts. Indeed, no comprehensive description of how strategy should be adapted to technological adaptations exists, or at least only a very limited one. The small amount of published quantitative research probably reflects the limited understanding people have about how different technologies relate to different organizational outcomes.

In order to provide a vantage point upon which such research efforts could be based, we offered a taxonomy 


\section{Beyond the Hype: A Bibliometric Analysis Deconstructing Research on Digitalization Andrea Holand, Silje Svadberg and Karl Joachim Breunig}

with a clear delimitation of interrelated terms and themes, emphasising the organizational and commercial implications of different related terms, rather than identifying the type of technology applied or degree of technological complexity involved. This taxonomy identifies the level of analysis associated with each of its constituent terms; digitization, digitalization and DT, connected in a step-wise process. For example, digitization is described as a stage that alone offers limited value in terms of improving operations, and thus digitized information is referred to as an aspect of digitalization.

A quite different term, digitalization is instead a general tool for BM innovation, as it can contribute to the shift from product to service based businesses. DT relates to the intra-organizational level, involving the external environment with implications for all three dimensions. Therefore, the taxonomy offers a vantage point for subsequent empirical and conceptual research to extend insights on related digitalization themes, especially related to innovation and strategy decisions on scalability, automation, channel selection and connectivity. Whereas extant research suggest that digitalization with its related terms Digitization and DT reflect both development stages and ambitions associated with the utilization of new technology, our taxonomy establishes a firm link to strategy, as suggested by Kane et al. (2015) on three distinct levels (activities, organizational process or organizational and ecosystem level). Deciding on digital innovation and digital strategy is currently of primary concern to practitioners when navigating an increasingly disruptive environment.

The implications for practice are to understand that digitalization is more strategic than technological. At all three levels, adopting technology has strategic implications. At the digitization level, data limited to one activity can provide opportunities for cost reduction. Digitization involves transforming analogous data, such as patient records in a hospital, to a digital format, and thus extending its potential for utilization through scalability, asynchronous, and spatial access. Digital transformation on the other hand has far reaching strategic implications, as utilising technology will involve organizational change, new value propositions and business models, and an ability to connect with partners across an ecosystem. The suggested taxonomy can thus provide a navigational tool for practitioners when deciding on digital innovation and digital strategy, and link these to the identified dimensions of challenges and opportunities (cost reduction, connectivity and value creation), across industries with different contextual complexities.

Our study condensed an overwhelming amount of digitalization research into a digestible 18 papers spanning across five interrelated disciplines. Moreover, we proposed a taxonomy that can be utilized to inform innovation and strategy discussions within firms when deciding on future directions for their digitalization efforts. In particular, our suggested taxonomy offers an explicit emphasis on organizational and commercial consequences of different digitalization ambitions. We suggest that managerial teams discussing the selection and implementation of digital technologies consider the organizational perspective underpinning our suggested taxonomy when addressing their digital innovation strategy in general, and in particular when deciding on BM innovation, digital disruption, DT, disruptive innovation, and Industry 4.0.

\section{References}

Andal-Ancion, A., Cartwright, P. A., \& Yip, G. S. 2003. The digital transformation of traditional business. MIT fISloan Management Review, 44(4) 34-41.

Aron, D., \& Waller, G. 2014. Taming the digital dragon: The 2014 CIO agenda. Gartner. https://www.gartner.com/en/documents/2643016/t aming-the-digital-dragon-the-2014-cio-agenda.

Bhimani, A., \& Willcocks, L. 2014. Digitisation,'Big Data'and the transformation of accounting information. Accounting Business Research, 44(4): 469-490.

Bradley, J., Loucks, J., Macaulay, J., Noronha, A., \& Wade, M. 2015. "Digital vortex: How digital disruption is redefining industries" Global Center for Digital Business Transformation: An IMD and Cisco initiative.

Brenner, W., Karagiannis, D., Kolbe, L., Krüger, J., Leifer, L., Lamberti, H. J., Leimeister, H. Ö., Petrie, C., Plattner, H., Schwabe, G., Uebernickel, F., Winter, R., \& Zarnekow, R. 2014. "User, use \& utility research" Business \& Information Systems Engineering, 6(1): 55-61.

Brynjolfsson, E., \& McAfee, A. 2014. "The second machine age: Work, progress, and prosperity in a time of brilliant technologies" WW Norton \& Company

Cook, D. J., Greengold, N. L., Ellrodt, A. G., \& Weingarten, S. R. 1997. "The relation between systematic reviews and practice guidelines" Annals of internal medicine, 127(3): 210-216.

Desai, D. R. 2013. The New Steam: On Digitization, Decentralization, and Disruption. Hastings, 65: 1469.

Gaigher, S., Le Roux, E., \& Bothma, T. 2014. "The predictive value of disruptive technology theory for 


\section{Beyond the Hype: A Bibliometric Analysis Deconstructing Research on Digitalization Andrea Holand, Silje Svadberg and Karl Joachim Breunig}

digital publishing in the traditional "publishing environment: A South African case study” Journal of Scholarly Publishing, 45(3): 261-288.

Heilig, L., Lalla-Ruiz, E., \& Voß, S. 2017. "Digital transformation in maritime ports: analysis and a game theoretic framework" NETNOMICS: Economic Research and Electronic Networking, 18(2-3): 227254.

Hess, T., Matt, C., Benlian, A., \& Wiesböck, F. 2016. Options for formulating a digital transformation strategy. MIS Quarterly Executive, 15(2).

Hänninen, M., Smedlund, A., \& Mitronen, L. 2018. Digitalization in retailing: multi-sided platforms as drivers of industry transformation. Baltic Journal of Management, 13(2): 152-168.

Jesuthasan, R., Malcolm, T., \& Zarkadakis, G. 2016. "Automation Will Make Us Rethink What a "Job" Really Is" Harvard Business Review, 12.

Janowski, T. 2015. Digital government evolution: From transformation to contextualization. Government Information Quarterly, 32(3): 221-223.

Kane, G. C., Palmer, D., Phillips, A. N., Kiron, D., \& Buckley, N. 2015. "Strategy, not technology, drives digital transformation" MIT Sloan Management Review and Deloitte University Press, 14: 1-25.

Kotarba, M. 2018. Digital transformation of business models. Foundations of Management, 10(1): 123-142.

Legner, C., Eymann, T., Hess, T., Matt, C., Böhmann, T., Drews, P., Mädche, A., Urbach, N., \& Ahlemann, F. 2017. "Digitalization: opportunity and challenge for the business and information systems engineering community" Business \& information systems engineering, 59(4): 301-308.

Liu, D.-Y., Chen, S.-W., \& Chou, T.-C. 2011. Resource fit in digital transformation: Lessons learned from the CBC Bank global e-banking project. Management Decision, 49(10): 1728-1742.

Loebbecke, C., \& Picot, A. 2015. "Reflections on societal and business model transformation arising from digitization and big data analytics: A research agenda" The Journal of Strategic Information Systems, 24(3): 149-157.

Loonam, J., Eaves, S., Kumar, V., \& Parry, G. 2018. Towards digital transformation: Lessons learned from traditional organizations. Strategic Change, 27(2): 101-109.

Lyytinen, K., Yoo, Y., \& Boland Jr, R. 2016. Digital product innovation within four classes of innovation networks. Information Systems Journal, 26(1): 47-75.

Manyika, J., Chui, M., Bughin, J., Dobbs, R., Bisson, P., \& Marrs, A. 2013. Disruptive technologies: Advances that will transform life, business, and the global economy (Vol. 180), San Francisco, CA: McKinsey Global Institute.

Markoulli, M., Lee, C. I., Byington, E., \& Felps, W. A. 2017. "Mapping Human Resource Management: Reviewing the field and charting future directions" Human Resource Management Review, 27(3): 367396.
McAfee, A. 2009. "Enterprise 2.0: New collaborative tools for your organization's toughest challenges" Boston, MA.: Harvard Business Press.

Moreau, F. 2013. The Disruptive Nature of Digitization: The Case of the Recorded Music Industry. International Journal of Arts Management, 15(2).

Nambisan, S., Lyytinen, K., Majchrzak, A., \& Song, M. 2017. Digital Innovation Management: Reinventing innovation management research in a digital world. MIS Quarterly Executive, 41(1).

Negroponte, N. 1995. Being Digital. New York: Vintage Books.

Ng, I. C., \& Wakenshaw, S. Y. 2017. "The Internet-ofThings: Review and research directions" International Journal of Research in Marketing, 34(1): 3-21.

Porter, A., Kongthon, A., \& Lu, J. C. 2002. "Research profiling: Improving the literature review" Scientometrics, 53(3): 351-370.

Schallmo, D., Williams, C. A., \& Boardman, L. 2017. Digital transformation of business models- Best practice, enablers, and roadmap. International Journal of Innovation Management, 21(08) 1740014.

Stoeckli, E., Dremel, C., \& Uebernickel, F. 2018. Exploring characteristics and transformational capabilities of InsurTech innovations to understand insurance value creation in a digital world. Electronic Markets, 28(3): 287-305

Tilson, D., Lyytinen, K., \& Sørensen, C. 2010. Research commentary- Digital infrastructures: The missing IS research agenda. Information systems research, 21(4): 748-759.

Tranfield, D., Denyer, D., \& Smart, P. 2003. “Towards a methodology for developing evidence-informed management knowledge by means of systematic review" British journal of management, 14(3): 207222.

Valenduc, G., \& Vendramin, P. 2017. Digitalisation, between disruption and evolution. European Review of Labour and Research, 23(2): 121-134.

Van Eck, N. J., Waltman, L., Dekker, R., \& van den Berg, J. 2010. "A comparison of two techniques for bibliometric mapping: Multidimensional scaling and VOS" Journal of the American Society for Information Science and Technology, 61(12): 2405-2416.

Van Eck, N. J., \& Waltman, L. 2014. "Visualizing bibliometric networks" In Measuring scholarly impact . Springer, Cham: 285-320.

Verbeek, A., Debackere, K., Luwel, M., \& Zimmermann, E. 2002. "Measuring progress and evolution in science and technology: The multiple uses of bibliometric indicators." International Journal of management reviews, 4(2): 179-211.

Wang, J., Li, M., Wang, H., \& Pan, Y. 2012. "Identification of essential proteins based on edge clustering coefficient" IEEE/ACM Transactions on Computational Biology and Bioinformatics, 9(4): 1070-1080. 


\section{Beyond the Hype: A Bibliometric Analysis Deconstructing Research on \\ Digitalization Andrea Holand, Silje Svadberg and Karl Joachim Breunig}

Yoo, Y., Boland Jr, R. J., Lyytinen, K., \& Majchrzak, A. 2012. Organizing for innovation in the digitized world. Organization Science, 23(5): 1398-1408.

Yoo, Y., Henfridsson, O., \& Lyytinen, K. 2010. Research commentary- the new organizing logic of digital innovation: an agenda for information systems research. Information systems research, 21(4): 724735.

Zott, C., \& Amit, R. 2017. "Business model innovation: How to create value in a digital world" GfK Marketing Intelligence Review, 9(1): 18-23.

\section{Appendix I}

List of articles selected for content analysis:

1. Agarwal, R., Gao, G., DesRoches, C., \& Jha, A. K. (2010). Research commentary- The digital transformation of healthcare: Current status and the road ahead. Information Systems Research, 21(4): 796-809.

2. Andal-Ancion, A., Cartwright, P. A., \& Yip, G. S. (2003). The digital transformation of traditional businesses. MIT Sloan Management Review, 44(4): 34-42.

3. Bhimani, A., \& Willcocks, L. (2014). Digitisation, 'Big Data' and the transformation of accounting information. Accounting and Business Research, 44(4): 469-490.

4. Desai, D. R. (2013). The new steam: On digitization, decentralization, and disruption. Hastings LJ, 65: 1469.

5. Gaigher, S., Le Roux, E., \& Bothma, T. (2014). The predictive value of disruptive technology theory for digital publishing in the traditional publishing environment: A South African case study. Journal of Scholarly Publishing, 45(3): 261-288.

6. Hänninen, M., Smedlund, A., \& Mitronen, L. (2018). Digitalization in retailing: multi-sided platforms as drivers of industry transformation. Baltic Journal of Management, 13(2): 152-168.

7. Heilig, L., Lalla-Ruiz, E., \& Voß, S. (2017). Digital transformation in maritime ports: analysis and a game theoretic framework. NETNOMICS: Economic Research and Electronic Networking, 18(2-3): 227254.

8. Hess, T., Matt, C., Benlian, A., \& Wiesböck, F. (2016). Options for formulating a digital transformation strategy. MIS Quarterly Executive, 15(2).

9. Holmström, J., \& Partanen, J. (2014). Digital manufacturing-driven transformations of service supply chains for complex products. Supply Chain Management: An International Journal, 19(4): 421430.

10. Janowski, T. (2015). Digital government evolution: From transformation to contextualization.

11. Kotarba, M. (2018). Digital transformation of business models. Foundations of Management, 10(1):
123-142.

12. Liu, D. Y., Chen, S. W., \& Chou, T. C. (2011). Resource fit in digital transformation: Lessons learned from the CBC Bank global e-banking project. Management Decision, 49(10): 1728-1742.

13. Loonam, J., Eaves, S., Kumar, V., \& Parry, G. (2018). Towards digital transformation: Lessons learned from traditional organizations. Strategic Change, 27(2): 101-109.

14. Moreau, F. (2013). The Disruptive Nature of Digitization: The Case of the Recorded Music Industry. International Journal of Arts Management, 15(2).

15. Sánchez, M. A. (2017). A framework to assess organizational readiness for the digital transformation. Dimensión Empresarial, 15(2), 27-40.

16. Schallmo, D., Williams, C. A., \& Boardman, L. (2017). Digital transformation of business models- Best practice, enablers, and roadmap. International Journal of Innovation Management, 21(08), 1740014.

17. Stoeckli, E., Dremel, C., \& Uebernickel, F. (2018). Exploring characteristics and transformational capabilities of InsurTech innovations to understand insurance value creation in a digital world. Electronic Markets, 28(3): 287-305.

18. Valenduc, G., \& Vendramin, P. (2017). Digitalisation, between disruption and evolution. Transfer: European Review of Labour and Research, 23(2): 121134. 


\section{Beyond the Hype: A Bibliometric Analysis Deconstructing Research on \\ Digitalization Andrea Holand, Silje Svadberg and Karl Joachim Breunig}

\begin{abstract}
About the Authors
Andrea Holand is a business consultant at the Norway office in the IT-consulting firm Columbus. Ms. Holand graduated with a MSc in Business Administration from Oslo Business School, Oslo Metropolitan University - OsloMet in 2019. The article "Beyond the Hype: A Bibliometric Analysis Deconstructing Research on Digitalization" is based on research for her masters dissertation conducted in collaboration with the research group on Digital Innovation and Strategic Competence in Organizations (DISCO), at Oslo Metropolitan University - OsloMet. Prior to enrolling into the graduate program at Oslo Business School Ms. Holand graduated with a BA in Business Administration in 2017 from the University of SouthEastern Norway with a specialization in innovation and entrepreneurship management.
\end{abstract}

Silje Svadberg is an analyst in PA Consulting in Norway. Ms Svadberg graduated with a MSc graduate in Business Administration at Oslo Business School, Oslo Metropolitan University OsloMet in 2019. The article "Beyond the Hype: A Bibliometric Analysis Deconstructing Research on Digitalization" is based on research for her masters dissertation conducted in collaboration with the research group on Digital Innovation and Strategic Competence in Organizations (DISCO), at Oslo Metropolitan University - OsloMet. Prior to enrolling into the graduate program at Oslo Business School Ms. Svadberg graduated with a BA in Business Administration from Oslo Business School in 2017. In her bachelor thesis, she focused on digitalization of the financial sector. Ms. Svadberg has worked as an IT consultant for a Nordic Microsoft partner, responsible for financial applications, in parallel with full time enrolment and progress in the graduate program at Oslo Business School.
Karl Joachim Breunig is a Full Professor of Strategic Management at the Oslo Business School, Oslo Metropolitan University -OsloMet, where he is heading the research group on Digital Innovation and Strategic Competence in Organizations (DISCO). He received his Ph.D. from BI Norwegian Business School, and holds a MSc from London School of Economics. Prof. Breunig's research concentrates on the interception of strategyand innovation theory, and involves topics such as service- and business model innovation as well as digitalization in knowledge intensive firms.

Citation: Holand, A., Svadberg, S. \& Breunig, K.-J. 2019.

Beyond the Hype: A Bibliometric Analysis Deconstructing Research on Digitalization. Technology Innovation Management Review, 9(10): 38-50.

http://doi.org/10.22215/timreview/1274 (cc) BY

Keywords: Bibliometric analysis; Business models; Digitization; Digitalization; Digital transformation; Disruption; Innovation; Taxonomy. 